\title{
A luz e suas tecnologias: um estudo da física
}

\author{
Light and some of its technologies; a study of the physics
}

\author{
Alexandre Tort*10 \\ ${ }^{1}$ Universidade Federal do Rio de Janeiro, Instituto de Física, Rio de Janeiro, RJ, Brasil
}

Recebido em 24 de Abril, 2018. Aceito em 26 de Abril, 2018.

Lançado ao final de 2017 pela editora da Universidade Estadual de Ponta Grossa, o livro A luz e algumas de suas tecnologias: um estudo da física é uma coletânea de artigos sobre a luz e suas interações com a matéria organizada por Carlos Alberto dos Santos, professor aposentado do Instituto de Física da Universidade Federal do Rio Grande do Sul e atualmente dedicado aos programas de aperfeiçoamento de professores do ensino médio patrocinados pela SBF. As contribuições que fazem parte da coletânea são divididas em duas partes distintas: a primeira parte com um número maior de contribuições do que a segunda, tem como foco alguns aspectos do desenvolvimento histórico relativos ao nascimento da física moderna, principalmente ao papel de Albert Einstein (1879-1955), sem sombra de dúvida, o físico mais importante do século passado e um dos grandes de todos os tempos. A segunda parte é dedicada às aplicações tecnológicas modernas como a fotônica não-linear e pinças óticas e aos estranhos efeitos provocados pelos jogos de luz e sombra gerados pela luz do Sol ao incidir sobre obstáculos. Comecemos pela primeira parte.

Embora saibamos que a mecânica quântica e suas extensões relatvísticas tenham múltiplas aplicações que vão desde a descrição da estrutura da matéria até às interações entre as partículas elementares, ela parece muitas vezes ter sido criada para descrever exclusivamente as interações entre a luz e a matéria, e a primeira parte da coletânea reflete esta impressão. Após uma descrição da trajetória científica e pessoal de Einstein pelo Prof. C. A. dos Santos, de uma visão geral do eletromagnetismo clássico de Maxwell e suas conexões com a luz pelo Prof. L. F. Ziebell e uma vista d'olhos sobre a relatividade restrita e as ondas gravitacionais da relatividade geral, chegamos, na opinião deste resenhador, ao cerne desta primeira parte que são as contribuições de C. A. dos Santos e F. Lang da Silveira (capítulo 4) sobre um célebre experimento virtual de Einstein e um apanhado (capítulo 5) sobre a introdução do conceito de fóton e até sua aceitação pela comunidade científica.

A contribuição de dos Santos e Lang da Silveira é uma exposição didática da resposta à pergunta: o que

*Endereço de correspondência: tort@if.ufrj.br acontece se um observador inercial for comóvel com uma onda eletromagnética? O que ele observará? Este gedanken experiment, muitas vezes apresentado en passant em sala de aula, é aqui minuciosamente discutido pelos autores e a lição final parece ser: os caminhos da criação teórica podem ser extremamente tortuosos e logo de difícil reconstituição. A contribuição que finaliza a primeira parte também é fascinante: o efeito fotoelétrico, as primeiras observações experimentais por Heinrich Hertz (1857-1894), sua exaustiva verificação experimental por Philipp Lennard (1862-1947) e a importância do potencial de contato, a introdução do conceito de fóton e a resistência oferecida pela comunidade e finalmente a sua aceitação são descritos de um modo didático e certamente constituem-se em uma leitura complementar valiosa para o estudante da física moderna. A rota percorrida até a incorporação do conceito de fóton à caixa de ferramentas da física teórica, no frigir dos ovos, dá ao leitor a impressão que Max Planck (1858-1947) tinha razão ao comentar sobre a aceitação de novas concepções da realidade física: deve haver uma substituição geracional para que estes tenham chances de aceitação.

A segunda parte da coletânea contém três contribuições. As duas primeiras são antes de tudo um convite aos estudantes em final de um curso de bacharelado em física para que considerem a ótica não linear ou as pinças óticas como áreas de pesquisa as quais poderiam dedicar-se em um programa de mestrado e/ou doutorado. O Prof. Cid Bartolomeu de Araújo inicia esta segunda parte com uma introdução à importante área da fotônica não linear deixando imediatamente claro ao leitor a importância da disciplina e as diferenças essenciais entre a ótica linear e a não linear que nasce com o o desenvolvimento do laser. É fascinante a possibilidade de que luz gere mais luz; laseres aleatórios são também uma opção muito atraente como área de pesquisa.

A segunda contribuição é do Prof. Antonio A. R. Neves e discute os conceitos fírsicos por trás das pinças óticas, isto é: a luz como agente capaz de exercer pressão e consequentemente forças de origem ótica sobre sistemas físicos que vão desde as leis da reflexão e refração, cometas, radiômetros até a moderna manipulação de átomos, moléculas e estruturas biológicas mais complexas, pas- 
sando pela vela solar - apresentada em um dos dezoito contos de ficção científica publicados em Vento Solar de Arthur C. Clarke 2] - e os feixes tratores de Jornada nas Estrelas e de Guerra nas Estrelas.

A terceira contribuição da segunda parte dos professores Fernando Lang da Silveira e Rolando Axt, de evidente caráter pedagógico, é voltada para alunos, professores e entusiastas dos fenômenos óticos do cotidiano. Ambos os autores são professores experientes e excelentes didatas e aqui discutem o intrigante jogo de luz e sombras que se formos suficientemente atentos, poderemos observar no dia a dia. É uma pena que algumas das fotos que acompanham o texto não estejam a altura deste; fotos coloridas e uma impressão em separado em papel apropriado seriam o acompanhamento perfeito.

Como um todo ou por partes selecionadas, nesta coletânea, o leitor, seja ele professor ou estudante, certamente encontrará um excelente complemento ao ensino de física moderna, aquele primeiro curso que fazemos antes de cursar a mecânica quântica propriamente dita, bem como uma melhor apreciação das interações da luz com a matéria.

\section{Referências}

[1] C.A. Santos, A luz e algumas de suas tecnologias: um estudo da física (Editora UEPG, Ponta Grossa, 2017).

[2] A.C. Clarke, Vento Solar (Editora Globo, Rio de Janeiro, 1973). 